University of Nebraska - Lincoln

DigitalCommons@University of Nebraska - Lincoln

Faculty Publications, Department of Psychology

Psychology, Department of

August 2002

\title{
Place Conditioning: What Does It Add to Our Understanding of Ethanol Reward?
}

Fred O. Risinger

Oregon Health \& Science University, risinger@ohsu.edu

Christopher L. Cunningham

Oregon Health \& Science University School of Medicine, cunningh@ohsu.edu

Rick A. Bevins

University of Nebraska-Lincoln, rbevins1@unl.edu

Frank A. Holloway

University of Oklahoma Health Sciences Center

Follow this and additional works at: https://digitalcommons.unl.edu/psychfacpub

Part of the Psychiatry and Psychology Commons

Risinger, Fred O.; Cunningham, Christopher L.; Bevins, Rick A.; and Holloway, Frank A., "Place Conditioning: What Does It Add to Our Understanding of Ethanol Reward ?" (2002). Faculty Publications, Department of Psychology. 47.

https://digitalcommons.unl.edu/psychfacpub/47

This Article is brought to you for free and open access by the Psychology, Department of at DigitalCommons@University of Nebraska - Lincoln. It has been accepted for inclusion in Faculty Publications, Department of Psychology by an authorized administrator of DigitalCommons@University of Nebraska - Lincoln. 


\title{
Place Conditioning: What Does It Add to Our Understanding of Ethanol Reward?
}

\author{
Fred O. Risinger, Christopher L. Cunningham, Rick A. Bevins, and Frank A. Holloway \\ This article describes the proceedings of a symposium at the 2001 RSA annual meeting in Montreal, \\ Quebec, Canada. The cochairs were Fred O. Risinger and Christopher L. Cunningham. Presentations \\ were as follows: (1) Place conditioning: understanding the motivational impact of stimuli, by Rick A. \\ Bevins; (2) Role of historical factors in ethanol place conditioning, by Frank A. Holloway; (3) Ethanol \\ place conditioning in mice: genetic and environmental influences, by Christopher L. Cunningham; and \\ (4) Utilization of place conditioning for understanding the neuropharmacology of the rewarding effects \\ of ethanol, by Fred O. Risinger.
}

Key Words: Ethanol, Conditioned Place Preference, Rats, Mice, Genetics.

$\mathrm{P}$ LACE-CONDITIONING PROCEDURES ARE BASED on the establishment of a Pavlovian relationship between distinctive environmental cues and some effects of a drug (Carr et al., 1989). Subsequent approach or withdrawal behaviors to drug-paired cues are thought to index drug motivational properties. A number of place-conditioning designs have established that many abused or self-administered (i.e., reinforcing) drugs will produce a conditioned place preference (CPP) (Carr et al., 1989; Hoffman, 1989; Tzschentke, 1998). This general paradigm has successfully been used to examine environmental, genetic, and neurochemical determinants of drug reward [including ethanol $(\mathrm{EtOH})]$. This symposium examined recent advances in our knowledge of EtOH reward on the basis of studies using the place-conditioning procedure. Dr. Rick Bevins reviewed methodological, empirical, and theoretical issues related to the use of this technique to study non-EtOH reinforcers. Dr. Frank Holloway described the role of historical factors in the development of EtOH-induced conditioned place aversion (CPA) and CPP in rats. Dr. Christopher Cunningham reviewed recent studies of genetic and environmental influences on EtOH place conditioning in mice. Finally, Dr. Fred Ris-

From the Department of Behavioral Neuroscience (FOR, CLC), Portland Alcohol Research Center, Oregon Health \& Science University, Portland, Oregon; the Department of Psychology (RAB), University of $\mathrm{Ne}$ braska-Lincoln, Lincoln, Nebraska; and the Oklahoma Center for Alcohol and Drug-Related Studies (FAH), University of Oklahoma Health Sciences Center, Oklahoma City, Oklahoma.

Received for publication May 20, 2002; accepted June 12, 2002.

Reprint requests: Fred O. Risinger, PhD, Department of Behavioral Neuroscience, L470, Oregon Health \& Science University, 3181 S.W. Sam Jackson Park Rd., Portland, OR 97201-3098; Fax: 503-494-6877; E-mail: risinger@ohsu.edu.

Copyright (C) 2002 by the Research Society on Alcoholism. Used by permission. DOI: 10.1097/01.ALC.0000029582.19240.14 inger addressed contributions of this procedure to our understanding of the neurobiology of EtOH reward.

\section{PLACE CONDITIONING: UNDERSTANDING THE MOTIVATIONAL IMPACT OF STIMULI}

\section{Rick A. Bevins}

Stimuli in the environment can affect an animal such that it is more likely to engage in approach or avoidance behaviors. Place conditioning has become a popular experimental preparation for studying these motivational shifts - especially those shifts produced by drugs of abuse (for reviews, see Bardo and Bevins, 2000; Carr et al., 1989, Tzschentke, 1998). The early popularity of place conditioning has been attributed to the relative ease with which place conditioning is established in the laboratory. This argument is partially true when the comparison preparation is drug self-administration. For instance, the purchasing/building cost of the apparatus is cheaper, the animals can receive drugs systemically (surgery is not necessary), and the duration required to establish place conditioning is shorter. This methodological comparison, however, should be taken with caution. For instance, early methodological comparisons between place conditioning and self-administration assumed that the preparations were measuring common processes. The data no longer support this notion (see below). Furthermore, this methodological comparison obscures the fact that there is much labor involved in establishing a standardized protocol in the laboratory. For example, given that a drug is differentially paired with one of two distinct environments, the apparatus has to be built, tested, modified, retested, and so on to ensure that there is no strong unconditioned preference for either environment under initial and extended exposure. Even in a well balanced apparatus, rats will display an unconditioned preference for an environment. Thus, a further methodological consideration includes whether to ignore these individual differ- 
ences and pair the drug with a randomly selected environment (unbiased design; see following paragraph) or to pair the drug with, say, the nonpreferred compartment (see below).

Using an unbiased design, we sought to find the effective dose range for intravenous (iv) cocaine. Male Sprague-Dawley rats were surgically prepared with a catheter into the left external jugular vein. After a recovery period, rats were confined for $10 \mathrm{~min}$ to the place-conditioning chamber twice a day on four consecutive days (each confinement separated by $6 \mathrm{hr}$ ). One daily confinement was in a white end compartment that had a mesh floor; the other confinement was in a black end compartment that had a rod floor. Rats received an iv infusion of cocaine $(0.1,0.3,0.45,0.6,0.9$, or $1.2 \mathrm{mg} / \mathrm{kg})$ in one end compartment (randomly selected) and saline in the other end compartment (i.e., unbiased procedure). Controls received an infusion of saline immediately upon placement in both end compartments. The day after the last confinement was a drug-free test for conditioning. Rats were placed in a center gray compartment and allowed free access to both end compartments for $10 \mathrm{~min}$. Controls and rats treated with 0.1 and $0.3 \mathrm{mg} / \mathrm{kg}$ of cocaine spent comparable time in both end compartments. In contrast, rats treated with $0.45 \mathrm{mg} / \mathrm{kg}$ of cocaine or more spent more time in the cocaine-paired environment (i.e., a cocaine CPP). This increase in time likely reflects rats' predisposed tendency to approach appetitive/rewarding stimuli. That is, the environment presumably acquires secondary rewarding value by virtue of being reliably paired with the rewarding effects of cocaine. Thus, the secondary rewarding effects of the environment evoke approach behavior, resulting in an increase in time spent in the paired environment (cf Ikemoto and Panksepp, 1999).

Although the bulk of place-conditioning research has examined abused drugs, the rewarding effects of such stimuli as food, water, wheel running, and copulatory opportunity have also received empirical attention. A recent example from our laboratory is the rewarding effects of novel stimulation. From a drug-abuse perspective, novelty reward is of interest given the positive correlation between novelty/ sensation seeking and drug use in humans (Zuckerman, 1994). An underlying assumption is that this higher drug use and abuse rate in novelty seekers reflects common neurobiological processes between novelty and drugs (Bardo et al., 1996). After initial pretests for compartment preference, rats received repeated access to a novel object while they were confined to the nonpreferred compartment (i.e., the end compartment in which the least amount of time was spent during the pretest). They received equal exposure to the preferred compartment without objects (i.e., biased design). In a subsequent choice test, rats increased their preference for the novelty-paired compartment according to within-subject and between-subject measures (Bevins and Bardo, 1999). If the object is familiar, then no systematic shift in preference occurs (Bevins et al., 2002). Subsequent work has shown that dopaminergic processes mediating expression of novelty reward are similar to those of cocaine (Besheer et al., 1999; Cervo and Samanin, 1995). Further, in a one-trial placeconditioning procedure, a dose of iv cocaine that does not produce a preference alone will condition a place preference when access to a novel object co-occurs with the administration of cocaine. Importantly, access to a novel object alone in this onetrial procedure is also insufficient to condition a place preference. This data pattern was taken to indicate that the rewarding effects of cocaine summate with novelty (Bevins, 2001).

The summation experiment between cocaine and novelty used a single conditioning trial. This sensitivity to a single stimulus exposure is an important, but underused, feature of the place-conditioning preparation. In addition to allowing researchers to assess the motivational effect of acute drug administration, this feature seems well suited for developmental and other time-sensitive research (e.g., drug withdrawal). Furthermore, humans readily display learning in a single trial; the ability of place-conditioning procedures to index learning after a single trial may provide some construct validity to this animal model. Related to the latter point is the clinical observation that retrospective reports on positive first drug experiences may predict vulnerability for drug abuse (Haertzen et al., 1983). We attempted a laboratory analog of this observation. Briefly, we first assessed the acute rewarding effect of iv amphetamine $(1 \mathrm{mg} / \mathrm{kg})$ in a place-conditioning situation with rats (i.e., first drug experience). These rats were then allowed to self-administer $30 \mu \mathrm{g}$ per infusion of amphetamine (i.e., chronic reinforcing effects). The shift in place preference conditioned by a single amphetamine infusion was not significantly correlated with subsequent self-administration (Bardo et al., 1999). This result, combined with other research (see Bardo and Bevins, 2000), emphasizes the importance of understanding the processes underlying the ability of abused drugs to produce conditioned shifts in preference (i.e., place conditioning), as well as understanding their ability to maintain drug-taking behavior (i.e., self-administration). That is, the place-conditioning preparation likely measures drug processes involved in the etiology of drug abuse distinct from self-administration.

\section{Role of Historical Factors in Ethanol Place Conditioning}

Frank A. Holloway Tolerance to EtOH develops when repeated exposure to a given dose results in a decreased effect for that dose and an increase in the dose required to reproduce the initial EtOH dose effect. Although EtOH tolerance and dependence may develop independently, a possible relationship may exist between tolerance and the subsequent increase in EtOH consumption, which could eventually produce physical dependence. For example, tolerance development to the reward properties of EtOH might set the occasion for increased EtOH intake. However, studies examining shifts in the magnitude of EtOH reward after extended EtOH exposure have re- 
ported mixed results (Carney et al., 1976; Karoly et al., 1978). An alternative hypothesis is that increased $\mathrm{EtOH}$ consumption is permitted or facilitated by tolerance development to some of EtOH's disruptive or dysphoric effects (Holloway et al., 1988). According to this account, tolerance contributes to or facilitates EtOH consumption by reducing the costs of drinking, thereby enhancing the relative reward value of EtOH. Clearly, the latter hypothesis requires research addressing the role of both behavioral and physiologic factors in the development of tolerance to EtOH's behaviorally disruptive effects and also the relationship between such tolerance development and EtOH's reward effects. The latter can be assessed with the EtOH placeconditioning assay, which provides an index of approach to or avoidance of EtOH-paired contexts.

In studies using a rat operant model, we have reported that the behavioral tolerance that developed to the rate-decreasing (and rate-increasing) effects of EtOH (a) lasted for up to 6 months (Bird et al., 1985; Bird and Holloway, 1989; Holloway et al., 1988); (b) was jointly dependent on intoxicated practice and on some threshold exposure to EtOH; (c) was paralleled by the emergence of baseline response rate increases (Bird and Holloway, 1989; Holloway and King, 1989); (d) was not present in chronic EtOH controls with no EtOH-related task experience (Holloway et al., 1989); (e) was not due to metabolic or distributional factors and was not dependent on the mode or context of EtOH administration; (Holloway et al., 1992a); and (f) was produced by postsession EtOH exposure (see below) that led to rate decreases up to $24 \mathrm{hr}$ later (Holloway and King, 1989; Holloway et al., 1992b, 1993). We hypothesize that (a) the effective condition for EtOH tolerance development in the operant task is an interaction between the EtOH dose and the functional demand placed on the organism; (b) if this interaction leads to an unfavorable consequence, e.g., loss of reinforcements, then the animal will be motivated to learn any compensatory behavior that counteracts EtOH's effects; (c) positive cross-tolerance effects will be found for any situations producing similar behavioral demands, and negativecross tolerance effects will be found for situations producing opposite behavioral demands; and (d) the last tolerance development sets the occasion for a positive hedonic shift in EtOH's motivational effects.

We and others (Gauvin et al., 1989, 1992, 1993a,b; Holloway et al., 1993) have also demonstrated that an EtOH induced homeostatic compensatory or "hangover" effect occurs approximately 12 to $24 \mathrm{hr}$ after an acute high-dose injection of EtOH. Also, we demonstrated that rats receiving chronic EtOH injections 20 to $22 \mathrm{hr}$ before a fixed-ratio (FR) operant task demonstrated an initial rate suppression (Holloway and King, 1989). The rats subsequently became tolerant to this EtOH delayed effect (EDE) and displayed cross-generalization of EDE tolerance to the immediate effects of presession $\mathrm{EtOH}$. These data suggested a complex interaction among behavioral, temporal, and conditioning factors operative during the development of
EtOH tolerance. We hypothesized that this tolerance derives largely from the learning of a compensatory behavioral adjustment to either the immediate or delayed effects of $\mathrm{EtOH}$ on behavior. It is unclear how the delayed effects of EtOH contribute to the development of tolerance to EtOH's direct intoxicating effects or whether it is specific to the rate-reducing effects of EtOH. It would be of interest to assess the relative contribution of the delayed effect phenomenon to the development of the rate-increasing and rate-decreasing effects of $\mathrm{EtOH}$. This delayed effect of acute EtOH treatment may be the result of homeostatic compensatory responses that oppose its direct intoxicating effects. However, the behavioral effects (i.e., rate reduction in an FR task) seem to be in the same direction as the intoxicating effects. In subsequent experiments, we demonstrated that at least part of the EDE is due to a general disruption of circadian rhythms, not dissimilar to jet lag (Gauvin et al., 1997a), with the potential for influencing EtOH consumption (Gauvin et al., 1997b) and physiology (Baird et al., 1998).

In some studies, tolerance may be mediated by behavioral adjustments that allow rewarding stimuli to be acquired. Tabakoff and Hoffman (1988) have suggested that repeated administration of $\mathrm{EtOH}$ may produce tolerance to certain aversive properties that would allow an individual to be more able to consume larger quantities of EtOH. Earlier studies in our laboratory have shown that the acquisition of the kind of behavioral tolerance described previously will produce EtOH CPP (Holloway et al., 1992a) and will block the acquisition of conditioned taste aversion (Gauvin and Holloway, 1992a), rather than the conditioned place and taste aversions seen in rats without such a history. Other behavioral histories also alter EtOH's hedonic effects. For example, prior acquisition of oral EtOH self-administration produces subsequent EtOH place preference, and prior establishment of an $\mathrm{EtOH}$ discriminative cue blocks the normally seen EtOH place aversion (Gauvin and Holloway, 1992b).

This paper extends our analysis of EtOH tolerance in a rat operant model to focus on the following questions. (a) What are the relative and interactive roles played by the EDE or EtOH's immediate effects on the development of behavioral tolerance with an FR operant task? (b) What are the relative contributions of tolerance development to the immediate, delayed, or immediate and delayed EtOH effects on subsequent changes in EtOH's positive or negative hedonic properties? (c) Specifically, are EtOH's rewarding or aversive properties (as measured by EtOH place learning) modulated by prior tolerance development to any of these effects of EtOH?

Phase I studies were designed to differentiate the contributions of the direct intoxicating effects and the delayed effects of EtOH on the development of tolerance to EtOH's direct effects on operant performance in rats. Using a $(3 \times 6)$ group $x$ treatment design, we determined behavioral dose-effect curves (DECs) for EtOH's direct intoxicating effects on performance of an FR-30 operant task, by using both cumulative and sin- 
gle-session procedures: (a) before a 30-day period of daily injections (DEC 1); (b) at the end of the period of daily injections (DEC-2); and (c) 1 month later (DEC-3). Phase I studies required five groups of rats ( $n=8$ per group): EI, EtOH's immediate effects only; ED, EtOH's delayed effects only; EID, EtOH's immediate and delayed effects; SC, saline control (no $\mathrm{EtOH}$ in phase I); and EC, EtOH control (no phase I practice during either ETOH's immediate or delayed effects.

Once stable performance was achieved in each group on their respective schedules and DEC-1 tests were completed, daily phase I EtOH injections commenced. The chronic dosing regimen comprised incremental injections over 4 weeks from initial doses of $1.25 \mathrm{~g} / \mathrm{kg}$ up to $2.0 \mathrm{~g} / \mathrm{kg}$. Only groups EI, ED, and EID and the EC groups received EtOH injections. The SC group received volume-equivalent injections of normal saline. In the cumulative dosing animals, a significant shift to the right in the DECs for ETOH's rate-decreasing effects were evident in the EID, EI, and ED groups, but not in the SC and EC groups. In the animals whose DECs were determined by separate single session tests, similar results were obtained, but with the EID group showing the greatest amount of tolerance.

Phase II studies assessed the effects of antecedent tolerance development on the relative hedonic valences of $\mathrm{EtOH}$ in the phase I groups by using the EtOH place-conditioning paradigm. If the hedonically positive properties of EtOH are somehow unmasked by or dependent on the development of behavioral tolerance, then the prior exposure from phase I should be sensitive enough to elicit the acquisition of a CPA or preference in phase II. The procedure involved pairing EtOH or vehicle in one of two distinctive side chambers during training sessions (two of each per week) followed by a no-injection test session with access to the center start compartment and the two side compartments. All sessions were 30 min long. Four EtOHand four water-conditioning sessions were conducted between each test.

We anticipated a significant place learning resulting from the prior drug and experiment history in this experiment. The development of behavioral tolerance under the schedule-controlled operant tasks in the proposed study may be associated with the concurrent development of tolerance to EtOH's aversive properties. In the cumulative-dosing study, the rank order for time spent on the EtOH-paired side of the chambers was group EID $>$ group EI $>$ group ED $>$ group EC $>$ group SC. In the rats tested with single-session tests, only the EID group showed marked EtOH place preference, with the EI and ED groups showing neither place preference nor place aversion and the SC group showing clear place aversion.

In summary, these sets of data indicate that (a) in EtOHnaive rats, $\mathrm{EtOH}$ produces both $\mathrm{CPA}$ and conditioned taste aversion; (b) the prior acquisition of tolerance to EtOH's decreasing effects on FR-30 operant performance blocks EtOHinduced conditioned taste aversion and, independent of context, produces EtOH-induced CPP; and (c) furthermore, the prior establishment of EtOH drug discrimination or self-administration, respectively, blocks EtOH-induced conditioned taste aversion and produces EtOH-induced CPP. From these studies, a final caveat is that prior EtOH exposure alone probably mitigates some of the negative hedonic effects of $\mathrm{EtOH}$ seen in EtOH place conditioning. Future studies must look at both prior EtOH/ behavior histories and at place conditioning under both EtOH's immediate and delayed effects. This is particularly true because we have reported a paradoxical place preference for EtOH's delayed, or hangover, effects (Gauvin et al., 1997c).

\section{Ethanol Place Conditioning in Mice: Genetic and Environ- mental Influences}

Christopher L. Cunningham Although it has been rather difficult to demonstrate EtOH-induced CPP in drug-naive rats, the literature now offers substantial evidence of such conditioning in mice. In the most commonly reported procedure, mice are exposed to a discriminative Pavlovian conditioning procedure in which distinctive tactile stimuli provided by the floor of the apparatus are paired with intraperitoneal injection of either EtOH [conditioned stimulus (CS) + trials] or saline (CS trials). After four or more pairings of each type, mice are given a choice test in which access to both sets of stimuli is allowed in the absence of EtOH. The general result of such tests is that mice spend more time on a target floor when it has previously been paired with EtOH than when it has not (e.g., Cunningham et al., 1992).

The strength of EtOH-induced CPP is known to be influenced by many variables. For example, CPP is positively related to EtOH dose (Risinger et al., 1994), even up to dose levels that result in loss of the righting reflex (Cunningham et al., 1992; Risinger and Oakes, 1996a). The initial observation of $\mathrm{CPP}$ at doses that produced loss of righting suggested that the critical time period for producing this learning was during the first few minutes after injection, when blood EtOH levels were increasing. A study of conditioning trial duration supported this suggestion, showing that EtOH-induced CPP was stronger with short (5-min) trial durations than with long (30-min) trial durations (Cunningham and Prather, 1992). The Pavlovian nature of EtOH-induced CPP is further supported by the observation that repeated postconditioning exposure to the CS + without EtOH results in extinction of CPP (Cunningham and Henderson, 2000).

Many studies have examined genetic influences on EtOHinduced CPP. For example, studies conducted with selectively bred mice have shown that sensitivity to EtOH-induced CPP is genetically correlated with sensitivity to EtOH's thermal effect (Cunningham et al., 1991) and EtOH withdrawal (Chester et al., 1998; Crabbe et al., 1992). There are also substantial differences in place conditioning across standard inbred strains 
(Cunningham et al., 1996) and recombinant inbred strains (Cunningham, 1995). Moreover, recent studies have shown that this procedure is able to detect differences produced by targeted gene mutation (e.g., Cunningham et al., 2000; Risinger et al., 1996, 2001). Of the more than six dozen genotypes that have been examined over the last 12 years, nearly $75 \%$ have been found to show CPP with EtOH. Thus far, we have not found any strain that shows CPA with EtOH with our standard training procedures.

A recent project has further confirmed the influence of genotype by the successful selective breeding of mice for differences in sensitivity to EtOH-induced CPP (Hill and Cunningham, 2001). B6D2F2 mice served as the parent population, and a mass selection strategy was used, although brother-sister matings were avoided. The mean percentage of time spent on the EtOH-paired floor was used as the phenotype, and bidirectional selection was continued for five generations. A significant difference between the high-place preference and lowplace preference lines emerged in the third generation and was maintained over the next two generations. Interestingly, a line difference in EtOH-stimulated activity emerged as a correlated response to selection (i.e., high-place preference mice showed greater EtOH-induced activity than low-place preference mice), although there was no line difference in basal activity. This finding raises the possibility of overlap in the genetic mechanisms that influence EtOH CPP and locomotor activation. However, it is not consistent with previous studies suggesting dissociation in the mechanisms underlying these traits (e.g., Risinger et al., 1994).

The time interval between $\mathrm{EtOH}$ injection and exposure to the $\mathrm{CS}$ has been found to have a profound influence on EtOHinduced place conditioning in mice. More specifically, injection of EtOH immediately or $30 \mathrm{~min}$ before the CS has consistently been found to produce CPP, whereas injection of EtOH immediately after (but not 15 or $60 \mathrm{~min}$ after) the CS has been found to produce CPA (Cunningham et al., 1997). Additional studies have shown that CPA produced by post-CS EtOH exposure is positively related to EtOH dose, inversely related to trial duration, reduced by CS-only extinction trials, and reduced by prior EtOH exposure (Cunningham and Henderson, 2000). The strength of EtOH-induced CPA also varies as a function of genotype (Cunningham and Ignatoff, 2000). The finding of aversion with post-CS drug exposure is not unique to $\mathrm{EtOH}$. We recently reported that CPA is also produced by post-CS injection of many different abused drugs, including nicotine, morphine, cocaine, amphetamine, and diazepam (Cunningham et al., 2001).

Genetic correlational analyses show no significant relationship between EtOH-induced CPP and EtOH-induced CPA, suggesting that these phenomena represent relatively independent effects of EtOH. However, EtOH-induced CPA is genetically correlated with $\mathrm{EtOH}$-induced conditioned taste aversion and EtOH consumption, suggesting overlap in the genes influencing these phenotypes. We currently hypothesize that EtOHinduced CPA is caused by the novelty of the rapid transition in drug state that occurs when EtOH and other abused drugs are injected. Pre-exposure to EtOH presumably reduces CPA by reducing the novelty of that rapid change in state (Cunningham et al., 2002).

In summary, a substantial body of literature shows that place conditioning provides a reliable measure of EtOH's rewarding effects in mice. EtOH-induced CPP is sensitive to genotype and several variables thought to influence Pavlovian conditioning. Thus, as will be illustrated in the next section, the model is well suited for studying the neurobiological mechanisms underlying EtOH's rewarding and aversive effects.

\section{Utilization of Place Conditioning for Understanding the Neu- ropharmacology of the Rewarding Effects of Ethanol}

Fred O. Risinger Several theories of drug abuse or addiction have attributed drug reward or reinforcement to specific neurotransmitter systems and neuroanatomical pathways (e.g., Koob, 1992; Samson and Harris, 1992; Wise, 1998). Drug reward, as well as the action of other rewarding stimuli (e.g., food), has often been attributed to activity in the mesolimbic dopamine system (Wise, 1996; Wise and Rompre, 1989). For example, dopamine D2 receptor function has been suggested as playing a general role in reward (Wise et al., 1978). However, more recently, dopaminergic systems have been suggested to mediate the production of instrumental responding rather than mediation of reward per se (Salamone et al., 1997). Although substantial data support the importance of dopaminergic systems in the rewarding effects of amphetamine and cocaine (Hoffman, 1989; LeMoal and Simon, 1991), it is less clear that other drugs of abuse operate in a similar manner (Koob, 1992). For example, although mice lacking dopamine D2 receptors drink less EtOH, this effect has been proposed to be due to a nonspecific reduction in response output (Risinger et al., 2000, 2001). Koob (1992) has proposed drug reward models emphasizing the importance of the nucleus accumbens and has further proposed an important role for $y$-aminobutyric acid (GABA)-A receptors in the acute reinforcing effects of sedative hypnotics and EtOH. Opioid and noradrenergic systems have also been suggested to be important for EtOH's rewarding or aversive effects (e.g., Amit and Brown, 1982; McBride et al., 1999; Weiss and Koob, 1991). Furthermore, a large body of literature has suggested that serotonin systems are important in EtOH preference (McBride and Li, 1998). For example, serotonergic systems in the dorsal raphe nucleus, with projections to the nucleus accumbens, have been proposed as one potential site of action mediating EtOH reward (McBride et al., 1989, 1990). 
Although it is clear that a number of neurotransmitter systems are importantly involved with EtOH reinforcement, no exclusive role for a specific neurotransmitter system has been established for EtOH's direct motivational effects. Several studies indicate the involvement of serotonin systems in EtOH preference (Maurel et al., 2000; McBride et al., 1989, 1995). Dopaminergic receptor systems also seem to have prominent importance for drug reinforcement (McBride et al., 1999; Wise, 1998), as well as GABA receptor systems and opioid receptor systems (Koob, 2000). Dopaminergic, GABAergic, serotonergic, and opioid drugs reduce operant responding for $\mathrm{EtOH}$ reinforcement or EtOH intake (Haraguchi et al., 1990; June et al., 1999; Middaugh and Bandy, 2000; Pfeffer and Samson, 1988).

The studies described herein have explored the role of several neurotransmitter systems in EtOH reward. As indicated in the previous section, several strains of mice readily acquire conditioned preference to floor cues paired with systemic exposure to EtOH. Many of our studies have used the relatively inexpensive Swiss-Webster mouse strain. Swiss-Webster mice acquire EtOH-induced CPP, although less readily than more sensitive strains such as DBA/2J (Risinger and Oakes, 1996a). In these studies, treatment with drugs having at least some neurotransmitter-specific actions occurs just before exposure to EtOH and the conditioning floor cues. Subsequently, preference testing determines the actions of these selected drugs on the acquisition of this response. In some cases, mutant mice lacking a neurotransmitter function of interest were also tested. Our procedure typically involves four to six conditioning trials, with preference testing after at least four trials. The apparatus allows for the assessment of locomotor activity, which, during conditioning, enables the determination of the influence of drugs on EtOH-stimulated activity. Our designs also include treatment with the drug in the absence of EtOH to determine the motivational effects of the drug per se. Thus, drug-treatment comparisons are based on data from groups receiving EtOH, drug treatment plus $\mathrm{EtOH}$, and drug treatment alone. Genotype comparisons in studies with mutant mice are based on groups of knock-out and wild-type mice receiving EtOH.

Several studies were devoted to the examination of serotonin systems. In general, a large body of data mentioned previously has indicated that serotonin systems are important for EtOH intake. However, changes in intake may reflect several processes. Decreased intake may reflect decreased experience of reward, increased experience of aversion, nonspecific anorexia, or nonspecific motor effects. For example, the serotonin uptake inhibitor fluoxetine, as well as other serotonin uptake inhibitors, reduce EtOH consumption (Gill and Amit, 1989). However, fluoxetine did not alter the acquisition of EtOH-induced CPP (Risinger, 1997). Fluoxetine did enhance the acquisition of EtOH-induced conditioned taste aversion and enhanced the discriminative stimulus properties of $\mathrm{EtOH}$ (Risinger, 1997). More receptor-specific serotonergic agents have also been tested. Mianserin, a 5-hydroxytryptamine-2 (5HT2) receptor antagonist, was found to enhance the magnitude of EtOH-induced CPP. This effect was not coupled with any nonspecific motivational actions, because groups of mice treated with mianserin alone did not show evidence of conditioning (Risinger and Oakes, 1996b). However, mianserin reduced locomotor activity during the conditioning trials, indicating that the dose used $(10 \mathrm{mg} / \mathrm{kg})$ was behaviorally active. Similar results have been seen with pindobind-5HT1A, a 5-HT1A antagonist, which also enhanced the acquisition of EtOH-induced CPP but did not influence EtOH-induced conditioned taste aversion, EtOH-stimulated activity, or EtOH behavioral sensitization (Risinger and Boyce, 2002). Interest in the role of 5-HT1B receptors for determining sensitivity to EtOH was encouraged by the report that 5-HT1B knock-out mice drink large quantities of EtOH (Crabbe et al., 1996). However, more recent articles suggest that this effect is modest at best (Bouwknect et al., 2000; Crabbe et al., 1999; Risinger et al., 1999b). 5HT1B knock-out mice were not able to acquire significant CPP to EtOH but readily demonstrated the acquisition of EtOH-induced conditioned taste aversion (Risinger et al., 1996).

Studies aimed at describing the role of dopamine receptor systems have also used both pharmacological manipulations and genotype comparisons. Dopamine systems feature prominently in drug-reward models (e.g., Koob et al., 1998). An early study revealed that haloperidol reduced EtOH-stimulated activity during conditioning but did not alter the acquisition of EtOH-induced CPP (Risinger et al., 1992a). Clozapine also did not change the acquisition of EtOH-induced CPP but reduced EtOH-stimulated activity (Thrasher et al., 1999). However, both haloperidol and clozapine reduced the acquisition of EtOH-induced conditioned taste aversion (Risinger et al., 1999a; Thrasher et al., 1999). In contrast, U99194A, a dopamine D3 antagonist, enhanced the acquisition of EtOH-induced CPP (Boyce and Risinger, 2000, 2002). These results together suggest limited involvement of dopamine D2 and D4 receptors in $\mathrm{EtOH}$ reward but a possible role for dopamine D3 receptors. However, studies with selected mutants do not provide data that completely overlap with outcomes based on pharmacological manipulations. For example, dopamine D2 receptor knock-out mice did not acquire EtOH-induced CPP (Cunningham et al., 2000). Similarly, mice lacking the intracellular signaling protein DARPP-32 did not acquire this response (Risinger et al., 2001).

Although serotonin and dopamine systems often feature prominently in drug-reward models, other neurochemical mechanisms seem important for EtOH reward. Several studies have explored the role of GABA-related systems. These include an early study using the benzodiazepine receptor inverse agonist RO 15-1788, which did not alter the acquisition 
of EtOH CPP (Risinger et al., 1992b). More recently, application of the GABAA antagonists bicuculline or picrotoxin enhanced the acquisition of EtOH CPP (Chester and Cunningham, 1999a), whereas the GABAB agonist baclofen had no effect (Chester and Cunningham, 1999b). Reducing corticosterone levels during conditioning via treatment with aminoglutethimide also had no effect on the acquisition of EtOH CPP (Chester and Cunningham, 1998). Treatment with the opioid antagonist naloxone did not alter acquisition of EtOH CPP (Cunningham, 1995), but it did enhance the extinction of this response (Cunningham et al., 1998). However, $\mu$-receptor knock-out mice show reduced acquisition of EtOH CPP (Hall et al., 2001). Finally, inhibition of nitric oxide synthase by treatment with 7-nitroindazole prevented the acquisition of EtOH CPP (Itzhak and Martin, 2000).

In summary, a growing collection of studies has been devoted to exploration of the neuropharmacological mechanisms responsible for EtOH reward measured in the place-conditioning paradigm. Several neurotransmitter receptor systems (5-HT1B, D1, D2, and $\mu$ opioid) are associated with reductions in EtOH CPP. Likewise, several neurotransmitter systems (5-HT1A, 5HT2, D3, and GABAA) are associated with increases of EtOH CPP. In some cases, neuropharmacological manipulations selectively influence the acquisition of EtOH CPP when compared with other procedures designed to assess the motivational effects of EtOH.

\section{SUMMARY}

This symposium provided an overview of several issues in the use of place conditioning as a tool for characterizing the motivational effects of EtOH. Dr. Rick Bevins presented several methodological considerations important for the design and interpretation of studies using place conditioning. For example, the apparent ease of using this procedure can be offset by difficulties in establishing reliable protocols in the laboratory. Furthermore, characteristics of the procedure related to the experience of novelty have the potential to interact with the rewarding effects of drugs. Finally, drug reward measured by place conditioning may not be subserved by the same processes controlling drug self-administration.

Dr. Frank Holloway discussed the importance of past experience with EtOH and subsequent changes in EtOH self-administration and EtOH reward. For example, tolerance development to behavioral disruption caused by EtOH is important for the development of EtOH-induced CPP in rats. In contrast, EtOH-naive rats show place aversion. Past experience with EtOH self-administration also serves to promote the development of EtOH CPP in rats.

Dr. Christopher Cunningham discussed the general finding that $\mathrm{EtOH}$ readily produces CPP in most mouse strains. In this species, EtOH CPP is dose-dependent and occurs most robustly with short-duration conditioning trials. Importantly, changing conditioning parameters such that EtOH exposure occurs after conditioning cue exposure results in the production of CPA in mice.

Dr. Fred Risinger reviewed the outcomes of studies designed to address the neuropharmacological mechanisms important for acquisition of EtOH CPP. Overall, these studies offer several instances of neurotransmitter-specific actions that increase EtOH reward and several examples of neurotransmitter mechanisms that reduce EtOH reward. These actions in most cases seem specific for EtOH reward measured via place conditioning compared with other responses, such as conditioned taste aversion, EtOH-stimulated activity, and EtOH drinking.

\section{REFERENCES}

Amit Z, Brown ZW (1982) Actions of drugs of abuse on brain reward systems: a reconsideration with specific attention to alcohol. Pharmacol Biochem Behav 17:232-238.

Baird TJ, Briscoe RJ, Vallett M, Vanacek SA, Holloway FA, Gauvin DV (1998) Phase response curve for ethanol: alterations in circadian rhythms of temperature and activity in rats. Pharmacol Biochem Behav $61: 1-15$.

Bardo MT, Bevins RA (2000) Conditioned place preference: what does it add to our preclinical understanding of drug reward? Psychopharmacology 153:31-43.

Bardo MT, Donohew RL, Harrington NG (1996) Psychobiology of novelty seeking and drug seeking behavior. Behav Brain Res 77:23-43.

Bardo MT, Valone JM, Bevins RA (1999) Locomotion and conditioned place preference produced by acute intravenous amphetamine: role of dopamine receptors and individual differences in amphetamine self-administration. Psychopharmacology 143:39 -46.

Besheer J, Jensen HC, Bevins RA (1999) Dopamine antagonism in a novel-object recognition and a novel-object place conditioning preparation with rats. Behav Brain Res 103:35-44.

Bevins RA (2001) Novelty seeking and reward: implications for the study of high-risk behaviors. Curr Dir Psychol Sci 10:189 -193.

Bevins RA, Bardo MT (1999) Conditioned increase in place preference by access to novel objects: antagonism by MK- 801 . Behav Brain Res 99:53-60.

Bevins RA, Besheer J, Palmatier MI, Jensen HC, Pickett KS, Eurek S (2002) Novel-object place conditioning: behavioral and dopaminergic processes in expression of novelty reward. Behav Brain Res 129:41-50.

Bird DC, Holloway FA (1989) Development and loss of tolerance to the effects of ethanol on DRL performance of rats. Psychopharmacology $97: 45-57$.

Bird DC, Holloway FA, Carney JM (1985) Schedule-controlled behavior as an index of development and maintenance of ethanol tolerance. Psychopharmacology 87:414-420.

Bouwknecht JA, Hijzen TH, van der Gugten J, Maes RAA, Hen R, Oliver B (2000) Ethanol intake is not elevated in male 5-HT1B receptor knockout mice. Eur J Pharmacol 403:95-98.

Boyce JM, Risinger FO (2000) Enhancement of ethanol reward by dopa $\neg$ mine D3 receptor blockade. Brain Res 880:202-206. Boyce JM, Risinger FO (2002) Dopamine D3 receptor blockade and the motivational effects of ethanol. Alcohol, in press.

Carney JM, Llewellyn ME, Woods JH (1976) Variable interval responding maintained by intravenous codeine and ethanol injections in the rhesus monkey. Pharmacol Biochem Behav 5:577-582.

Carr GD, Fibiger HC, Phillips AG (1989) Conditioned place preference as a measure of drug reward, in The Neuropharmacological Basis of Reward (Liebman JM, Cooper SJ eds), pp 264 -319. Clarendon 
Press, Oxford.

Cervo L, Samanin R (1995) Effects of dopaminergic and glutamatergic antagonists on the acquisition and expression of cocaine conditioning place preference. Brain Res 673:242-250.

Chester JA, Cunningham CL (1998) Modulation of corticosterone does not affect the acquisition or expression of ethanol-induced conditioned place preference in DBA/2J mice. Pharmacol Biochem Behav 59:67-75.

Chester JA, Cunningham CL (1999a) GABA(A) receptors modulate ethanol-induced conditioned place preference and taste aversion in mice. Psychopharmacology 144:363-372.

Chester JA, Cunningham CL (1999b) Baclofen alters ethanol-stimulated activity but not conditioned place preference or taste aversion in mice. Pharmacol Biochem Behav 63:325-331.

Chester JA, Risinger FO, Cunningham CL (1998) Ethanol reward and aversion in mice bred for sensitivity to ethanol withdrawal. Alcohol Clin Exp Res 22:468 - 473 .

Crabbe JC, Phillips TJ, Cunningham CL, Belknap JK (1992) Genetic determinants of ethanol reinforcement. Ann NY Acad Sci 654:302310.

Crabbe JC, Phillips TJ, Feller DJ, Hen R, Wenger CD, Lessov CN, Schafer GL (1996) Elevated alcohol consumption in null mutant mice lacking 5-HT1b receptors. Nat Genet 14:98 -101.

Crabbe JC, Wahlstein D, Dudek BC (1999) Genetics of mouse behavior: interactions with laboratory environment. Science 284:1670 -1672.

Cunningham CL (1995) Localization of genes influencing ethanol-induced conditioned place preference and locomotor activity in BXD recombinant inbred mice. Psychopharmacology 120:28 -41.

Cunningham CL, Hallett CL, Niehus DR, Hunter JS, Nouth L, Risinger FO (1991) Assessment of ethanol's hedonic effects in mice selectively bred for sensitivity to ethanol-induced hypothermia. Psychopharmacology 105:84 -92.

Cunningham CL, Henderson CM (2000) Ethanol-induced conditioned place aversion in mice. Behav Pharmacol 11:591-602.

Cunningham CL, Howard MA, Gill SJ, Rubinstein M, Low MJ, Grandy DK (2000) Ethanol-conditioned place preference is reduced in dopa $\neg$ mine D2 receptor-deficient mice. Pharmacol Biochem Behav 67:693-699.

Cunningham CL, Ignatoff DL (2000) Genetic differences in ethanol-induced conditioned place aversion (abstract). Alcohol Clin Exp Res 24:57A.

Cunningham CL, Niehus DR, Malott DH, Prather LK (1992) Genetic differences in the rewarding and activating effects of morphine and ethanol. Psychopharmacology 107:385-393.

Cunningham Cl, Prather LK (1992) Conditioning trial duration affects ethanol-induced conditioned place preference in mice. Anim Learn Behav 20:187-194.

Cunningham CL, Okorn DM, Howard CE (1996) Ethanol-induced conditioned place preference and activation in 15 inbred mouse strains (abstract). Alcohol Clin Exp Res 20:59A.

Cunningham CL, Okorn DM, Howard CE (1997) Interstimulus interval determines whether ethanol produces conditioned place preference or aversion in mice. Anim Learn Behav 25:31-42.

Cunningham CL, Tull LE, Lee LE, Clemans JM (2001) Post-CS injection of abused drugs produces conditioned place aversion (abstract 27; program No. 647.19). Soc Neurosci.

Cunningham CL, Tull LE, Rindal KE, Meyer PJ (2002) Distal and proximal pre-exposure to ethanol in the place conditioning task: tolerance to aversive effect, sensitization to activating effect, but no change in rewarding effect. Psychopharmacology 160:414 -424.

Cunningham CL, Henderson CM, Bormann NM (1998) Extinction of ethanol-induced conditioned place preference and conditioned place aversion: effects of naloxone. Psychopharmacology 139:62-70.
Gauvin DV, Baird TJ, Vanacek SA, Briscoe RJ, Vallett M, Holloway FA (1997a) The effects of time-of-day and photoperiod phase-shifts on voluntary ethanol consumption in rats. Alcohol Clin Exp Res 21:817-825.

Gauvin DV, Briscoe RJ, Baird TJ, Vallett M, Carl KL, Holloway FA (1997b) Cross-generalization of ethanol hangover cue to endogenously-and exogenously-induced stimuli. Pharmacol Biochem Behav 57:199-206.

Gauvin DV, Briscoe RJ, Baird TJ, Vallett M, Holloway FA (1997c) The paradoxical hedonic valence of acute ethanol withdrawal (hangover) states in rats: place and taste conditioning. Alcohol 14:261-268.

Gauvin DV, Cheng E, Holloway FA (1993a) Biobehavioral correlates of alcohol hangover, in Recent Developments in Alcoholism: Ten Years of Progress (Galanter M ed), pp 281-304. Plenum Press, New York.

Gauvin DV, Goulden KL, Holloway FA (1993b) State dependent operant stimulus control: cueing attributes of ethanol hangover in rats. Alcohol Clin Exp Res 17:1210-1214.

Gauvin DV, Harland RD, Criado JR, Michaelis RC, Holloway FA (1989) The discriminative stimulus properties of ethanol and acute ethanol withdrawal states in rats. Drug Alcohol Depend 24:103-113.

Gauvin DV, Holloway FA (1992a) Ethanol tolerance developed during intoxicated operant performance in rats prevents subsequent ethanolinduced conditioned taste aversion. Alcohol 9:167-170.

Gauvin DV, Holloway FA (1992b) Historical factors in the development of ETOH conditioned place learning. Alcohol 9:1-7.

Gauvin DV, Youngblood BD, Holloway FA (1992) The discriminative stimulus properties of acute ethanol withdrawal (hangover) in rats. Alcohol Clin Exp Res 16:336 -341.

Gill K, Amit Z (1989) Serotonin uptake blockers and voluntary ethanol consumption: a review of recent studies, in Recent Developments in Alcoholism (Galanter M ed), pp 225-253. Plenum, New York.

Haertzen CA, Kocher TR, Miyasato K (1983) Reinforcements from the first drug experience can predict later drug habits and/or addiction: results with coffee, cigarettes, alcohol, barbiturates, minor and major tranquilizers, stimulants, marijuana, hallucinogens, heroin, opiates and cocaine. Drug Alcohol Depend 11:147-165.

Hall FS, Sora I, Uhl GR (2001) Ethanol consumption and reward are decreased in mu-opiate receptor knockout mice. Psychopharmacology 154:43-49.

Haraguchi M, Samson HH, Tolliver GA (1990) Reduction in oral ethanol self-administration in the rat by the 5-HT uptake blocker fluoxetine. Pharmacol Biochem Behav 35:259 -262.

Hill KG, Cunningham CL (2001) Selective breeding for high and low ethanol place preference (abstract 27; program No. 444.1). Soc Neuro-sci.

Hoffman DC (1989) The use of place conditioning in studying the neuropharmacology of drug reinforcement. Brain Res Bull 23:373-387.

Holloway FA, Bird DC, Holloway JA, Michaelis RC (1988) Behavioral factors in the development of tolerance to ethanol's effects. Pharmacol Biochem Behav 29:105-113.

Holloway FA, King DA (1989) Parallel development of ethanol tolerance and operant compensatory behaviors in rats. Pharmacol Biochem Behav 34:855-861.

Holloway FA, King DA, Bedingfield JB, Gauvin DV (1992a) Role of context in ethanol tolerance and subsequent hedonic effects. Alcohol 9:109-116.

Holloway FA, King DA, Michaelis RC, Harland RD, Bird DC (1989) Tolerance to ethanol's disruptive effects on operant behavior in rats. Psychopharmacology 99:479-485.

Holloway FA, Michaelis RC, Harland RD, Criado JR, Gauvin DV (1992b) Tolerance to ethanol's effects on operant performance in rats: role of number and pattern of intoxicated practice opportunities. Psychopharmacology 109:112-120. 
Holloway FA, Miller JM, King DA, Bedingfield JB (1993) Delayed ethanol effects on physiological and behavioral indices in the rat. Alcohol 10:511-519.

Ikemoto S, Panksepp J (1999) The role of nucleus accumbens dopamine in motivated behavior: a unifying interpretation with special reference to reward-seeking. Brain Res Brain Res Rev 31:6 -41.

Itzhak Y, Martin JL (2000) Blockade of alcohol-induced locomotor sensitization and conditioned place preference in DBA mice by 7-nitroindazole. Brain Res 858:402-407.

June HL, McCane SR, Zink RW, Portoghese PS, Li T-K, Froehlich JC (1999) The delta 2-opioid receptor antagonist naltriben reduces motivated responding for ethanol. Psychopharmacology 147:81-89.

Karoly AJ, Winger G, Ikomi R, Woods JH (1978) The reinforcing property of ethanol in the rhesus monkey II. Some variables related to the maintenance of intravenous ethanol-reinforced responding. Psychopharmacology 58:19-25.

Koob GF (1992) Neural mechanisms of drug reinforcement. Ann NY Acad Sci 654:171-191.

Koob GF (2000) Neurobiology of addiction. Toward the development of new therapies. Ann NY Acad Sci 909:170 -185.

Koob GF, Roberts AJ, Schulteis G, Parsons LH, Heyser CJ, Hyytia P, Merlo-Pich E, Weiss F (1998) Neurocircuitry targets in ethanol reward and dependence. Alcohol Clin Exp Res 22:3-9.

Le Moal M, Simon H (1991) Mesocorticolimbic dopaminergic network: functional and regulatory roles. Physiol Rev 71:155-234.

Maurel S, De Vry J, Schreiber R (2000) Comparison of the effects of the selective serotonin-reuptake inhibitors fluoxetine, paroxetine, citalopram and fluvoxamine in alcohol preferring cAA rats. Alcohol 17:195- 201.

McBride WJ, Bodart B, Lumeng L, Li T-K (1995) Association between low contents of dopamine and serotonin in the nucleus accumbens and high alcohol preference. Alcohol Clin Exp Res 19:1420 -1422.

McBride WJ, Li T-K (1998) Animal models of alcoholism: neurobiology of high alcohol drinking behavior in rodents. Crit Rev Neurobiol 12: 339-369.

McBride WJ, Murphy JM, Ikemoto S (1999) Localization of brain reinforcement mechanisms: intracranial self-administration and intracranial place-conditioning studies. Behav Brain Res 101:129 -152.

McBride WJ, Murphy JM, Lumeng L, Li T-K (1989) Serotonin and ethanol preference, in Recent Developments in Alcoholism (Galanter M ed), pp 187-223. Plenum, New York.

McBride WJ, Murphy JM, Lumeng L, Li T-K (1990) Serotonin, dopamine and GABA involvement in alcohol drinking of selectively bred rats. Alcohol 7:199-205.

Middaugh LD, Bandy AL (2000) Naltrexone effects on ethanol consumption and response to ethanol conditioned cues in C57BL/6 mice. Psychopharmacology 151:321-327.

Pfeffer AO, Samson HH (1988) Haloperidol and apomorphine effects on ethanol reinforcement in free feeding rats. Pharmacol Biochem Behav 29:343-350.

Risinger FO (1997) Fluoxetine's effects on ethanol's rewarding, aversive and stimulus properties. Life Sci 61:PL235-242.

Risinger FO, Bormann NM, Oakes RA (1996) Reduced sensitivity to ethanol reward, but not ethanol aversion in mice lacking 5-HT1b receptors. Alcohol Clin Exp Res 20:1401-1405.
Risinger FO, Boyce JM (2002) 5-HT1A receptor blockade and the motivational profile of ethanol. Life Sci 71:707-715.

Risinger FO, Brown MM, Oakes RA, Love JL (1999a) Effects of haloperidol or SCH-23390 on ethanol induced conditioned taste aversion. Alcohol 18:139-145.

Risinger FO, Doan AM, Vickrey AC (1999b) Oral operant ethanol selfadministration in 5-HT1b knockout mice. Behav Brain Res 102:211215.

Risinger FO, Dickinson SD, Cunningham CL (1992a) Haloperidol reduces ethanol-induced motor stimulation but not conditioned place preference. Psychopharmacology 107:453-456.

Risinger FO, Freeman PA, Greengard P, Fienberg AA (2001) Motivational effects of ethanol in DARPP-32 knock-out mice. J Neurosci 21:340 348.

Risinger FO, Freeman PA, Rubinstein M, Low M, Grandy DK (2000) Lack of oral ethanol self-administration in dopamine D2 receptor knockout mice. Psychopharmacology 152:343-350.

Risinger FO, Malott DH, Prather LK, Niehus DR, Cunningham CL (1994) Motivational properties of ethanol in mice selectively bred for ethanol-induced locomotor differences. Psychopharmacology 116:207216.

Risinger FO, Malott DH, Riley AL, Cunningham CL (1992b) Effect of Ro 15-4513 on ethanol-induced conditioned place preference. Pharmacol Biochem Behav 43:97-102.

Risinger FO, Oakes RA (1996a) Dose-and conditioning-trial dependent ethanol-induced conditioned place preference in Swiss-Webster mice. Pharmacol Biochem Behav 55:117-123.

Risinger FO, Oakes RA (1996b) Mianserin enhancement of ethanol-induced conditioned place preference. Behav Pharmacol 7:294 -298.

Salamone JD, Cousins MS, Snyder BJ (1997) Behavioral functions of nucleus accumbens dopamine: empirical and conceptual problems with the anhedonia hypothesis. Neurosci Biobehav Rev 21:341-359.

Samson HH, Harris RA (1992) Neurobiology of alcohol abuse. Trends Pharmacol Sci 13:206-211.

Tabakoff B, Hoffman PL (1988) Tolerance and the etiology of alcoholism: hypothesis and mechanism. Alcohol Clin Exp Res 12:184-186.

Thrasher MJ, Freeman PA, Risinger FO (1999) Clozapine effects on ethanol's motivational properties. Alcohol Clin Exp Res 23:1377-1385.

Tzschentke TM (1998) Measuring reward with the conditioned place preference paradigm: a comprehensive review of drug effects, recent progress and new issues. Prog Neurobiol 56:613-672.

Weiss F, Koob GF (1991) The neuropharmacology of ethanol self-administration, in Neuropharmacology of Ethanol (Meyer RE, Koob GF, Lewis MJ, Paul SM eds), pp 125-162. Birkhauser, Boston.

Wise RA (1996) Neurobiology of addiction. Curr Opin Neurobiol 6:243-

251. Wise RA (1998) Drug-activation of brain reward pathways. Drug Alcohol Depend 51:13-22. Wise RA, Rompre P-P (1989) Brain dopamine and reward. Annu Rev Psychol 40:191-225.

Wise RA, Spindle J, deWit H, Gerberg GJ (1978) Neuroleptic-induced "anhedonia" in rats: pimozide blocks reward quality of food. Science 201:262-264.

Zuckerman M (1994) Behavioral Expressions and Biosocial Bases of Sensation Seeking. Cambridge University Press, New York. 